\title{
Percepção de casais heterossexuais em relação à suscetibilidade de infecção por HIV/AIDS
}

\author{
Lirene Finkler \\ Pricilla Braga \\ William B. Gomes \\ Universidade Federal do Rio Grande do Sul
}

\begin{abstract}
RESUMO
Dificuldades na prática de sexo seguro em relacionamentos heterossexuais estáveis apontam para a necessidade de estudos que desloquem o foco do individual para o interacional. $\mathrm{O}$ estudo entrevistou 15 casais heterossexuais, com relacionamento estável de no mínimo um ano, que se apresentaram voluntariamente para testagem para HIV, em um serviço de saúde pública, entre os anos de 2001 e 2002. A entrevista versou sobre as negociações do casal para a prática de sexo seguro. A descrição qualitativa indicou que os casais apresentaram diferentes graus de clareza quanto à suscetibilidade de risco: 1) afirmação de não suscetibilidade; 2) admissão de suscetibilidade; e 3) inserção contraditória e ambígua. A análise indutiva ou temática concentrou-se em dois aspectos da suscetibilidade contraditória e ambígua: suspeita de contaminação por hábitos prévios e/ou remanescentes, e franqueza com o parceiro quanto aos cuidados de prevenção. A análise crítica ou interpretação mostrou que padrões relacionais entre gêneros fazem com que as mulheres abdiquem da prevenção em favor da manutenção do relacionamento. Por outro lado, os homens aumentam sua susceptibilidade ao manter padrões de comportamentos considerados viris. (FAPERGS).
\end{abstract}

Palavras-chave: HIV/AIDS; relacionamentos conjugais.

\begin{abstract}
Perception of heterosexual couples regarding susceptibility of infection by HIV/AIDS

Difficulties in the practice of safe sexual intercourse by stable heterosexual couples pointed out the need for studies that change the focus from the individual to the relationship itself. The present study interviewed 15 heterosexual couples that presented themselves voluntary for HIV testing, at a public health service, between the years of 2001 and 2002. The interview asked about couple's negotiation on using safe methods for sexual intercourse. The qualitative description showed that the couples presented three different levels of understanding on risk of susceptibility to acquiring AIDS: 1) denying the risk, 2) admitting the risk, and 3) ambivalence about the risk. Subsequent inductive analysis concentrated upon two implications of ambivalence: suspicion of contamination from previous or remaining habits, and a lack of directness in talking about means of prevention. The critical analysis concluded that there was a relational pattern between the sexes. A crucial point for women, in avoiding the use of preventive means, was the need acquiesce to the man's preference in to keep a relationship. In contrast, men increased their susceptibility to AIDS by assuming avoidance was a sign of their virility.
\end{abstract}

Keywords: HIV/AIDS; marital relationships.

O presente estudo analisa o contexto da prevenção e da negociação para a prática de sexo mais seguro, permeada pela procura por testagem voluntária para HIV/AIDS em casais. Testagem e aconselhamento voluntário, e pré e pós-teste são alternativas preventivas utilizadas mundialmente (Chippindale \& French, 2001). O potencial preventivo desses procedimentos tem sido reconhecido por estudiosos e profissionais de países EUA, Tailândia, Brasil, e em especial no continente africano, estando associados com redução de comportamento de risco e com menores taxas de soroconversão entre casais sorodiscordantes (Painter, 2001; Roth \& cols., 2001). A decisão de testar-se é influenciada por fatores individuais, relacionais e ambientais, sendo o medo da reação do parceiro e dificuldades de comunicação entre o casal importantes barreiras para o compartilhamento do resultado do exame (Maman, Mbwambo, Hogan, Kilonzo \& Sweat, 2001).

Inicialmente, as intervenções preventivas globais não estiveram voltadas especificamente para a prevenção em relações conjugais ou uniões consensuais consideradas estáveis, uma vez que a monogamia implícita nessas relações era considerada fator de proteção (Campos, 1998). A exclusão das relações estáveis do foco das abordagens preventivas modificou-se na década de 90, com a crescente feminização da epidemia em relações heterossexuais. Buscou-se, então, adaptar as táticas gerais de prevenção à realidade dos relacionamentos heterossexuais estáveis, enfatizando o uso de preservativos como referencial de sexo mais seguro. Esse modelo, que surgiu dos grupos homossexuais americanos, utiliza forte apelo à proteção do corpo e à 
responsabilidade mútua, agregando sentido erótico ao do uso do preservativo. Tal estratégia preventiva vem apresentando baixa eficácia em países emergentes, como é o caso do Brasil, por não levar em conta as características da cultura sexual e os contextos socioculturais, onde as decisões são tomadas. Por exemplo, a ênfase na decisão e motivação individual são características das intervenções preventivas desenvolvidas na América do Norte e Europa, mas essas noções de autonomia e responsabilidade individual são estranhas à cultura brasileira, sendo questionável a adequação da estratégia (Knauth, 1997; Pimenta, Passarelli, Brito \& Parker, 2002). Assim, o casamento e as relações em longo prazo são vistos como incompatíveis com o uso de preservativos, já que sua utilização sugere a ruptura com o modelo monogâmico de sexualidade no casamento (Both, 1997). Guimarães (1994) afirmou que homens e mulheres "consideram o uso de preservativos mais apropriado para relações casuais ou em fase inicial de conhecimento, sobretudo como método contraceptivo" (p. 224). Entretanto, mesmo nesses casos, a utilização de preservativos está longe de ser sistemática. Um estudo que examinou a freqüência de sexo extraconjugal e risco de infecção por HIV entre americanos adultos casados, por exemplo, encontrou baixos níveis de uso de camisinha entre os sujeitos que referiram sexo extraconjugal (Choi, Catania \& Dolcini, 1994). Da mesma forma, estudo sobre o comportamento sexual da população brasileira indicou alto índice de exposição entre os sexualmente ativos, principalmente pelo não uso de preservativos nas parcerias estáveis (Brasil, 2000).

A negociação do sexo mais seguro tem se mostrado de difícil implementação em relacionamentos heterossexuais de longa data, nos quais a monogamia não pode ser garantida (Maxwell \& Boyle, 1995; Obbo, 1993; Pitts, Bowman \& McMaster, 1995). Colaboram, neste sentido, as questões de gênero, ou seja, a construção social do masculino e do feminino. $\mathrm{O}$ estabelecimento do masculino como ativo e do feminino como passivo organiza as interações $\mathrm{e}$ as possibilidades de negociação relacionadas ao sexo. Diversos estudos, em diferentes culturas, indicam que esse desequilíbrio de poder é um aspecto importante nas decisões das mulheres quanto ao sexo mais seguro, principalmente aquelas acima dos 30 anos (Maxwell \& Boyle, 1995). O padrão moral diferenciado para os sexos, naturalizando a prática sexual extraconjugal masculina, é comum em diferentes culturas. A conclusão apóia-se em pesquisas realizadas em países africanos, como Zimbabwe (Pitts \& cols., 1995) e Uganda (Obbo, 1993), sul-americanos, como mostram pesquisas brasileiras (Both, 1997; Campos, 1998; Knauth, 1997), norte-americanos (Levine \& cols., 1993) e europeus (Buunk \& Bakker, 1997). Com exceção de Buunk e Bakker (1997) que consideram esses padrões sexuais diferenciados em termos estritamente da teoria da evolução das espécies, os demais assumem uma visão sociocultural, sugerindo que a redefinição dos papéis de gênero é possível e necessária para o estabelecimento de práticas de negociação preventiva efetivas.
O desequilíbrio de poder, isto é um homem que decide e uma mulher dócil que aceita, torna a negociação de sexo mais seguro um sério problema para as mulheres (Campos, 1998). A construção do masculino como ativo e do feminino como passivo organiza as interações e as possibilidades de negociação relacionadas ao sexo. Oprimidas na relação, elas apresentam dificuldades em apontar alternativas de prevenção, mesmo sabendo das práticas sexuais extraconjugais de seus parceiros (Barbosa, 1995). A noção de risco estaria profundamente vinculada aos atributos femininos de passividade e fidelidade. Tais atributos colocam as mulheres em risco de serem marcadas por estigmas quando ousam ser ativas, questionando e propondo práticas sexuais, como o uso de preservativo (Both, 1997). Tal situação configuraria o desequilíbrio de poder, no caso, o domínio da relação sexual pelo homem.

A negociação para prática de sexo mais seguro exige dos casais um conjunto de trocas comunicativas muito específicas. Como um sistema, o casal desenvolve mecanismos de regulação emocional e comportamental próprios, definidos, em grande parte, na comunicação. $O$ estabelecimento da relação envolve acordos conscientes e inconscientes e a definição de regras de interação dos indivíduos entre si, assim como do casal com os sistemas familiares e sociais circundantes. As regras relacionais são as mediadoras da interação, definem a qualidade da comunicação, a compreensão da realidade e o conceito de si (Anton, 1998, 2002).

Neste estudo, utilizou-se o período da testagem como marco revelatório dos aspectos experienciais de casais que se apresentaram para realizar juntos a testagem para HIV. A pesquisa orientou-se pelas seguintes perguntas: 1) $\mathrm{O}$ que levou os casais a procurarem a testagem? 2) O que os casais conhecem sobre HIV/AIDS? 3) Os casais conversam, em seus momentos de intimidade, sobre os riscos do HIV/AIDS? 4) Há um reconhecimento do grau de risco associado ao estilo de vida do casal? 5) Como está sendo estabelecida a relação de cuidado consigo mesmo e com o outro na parceria conjugal? A premissa básica da pesquisa é que o cuidado de si e do outro na parceria conjugal, diante da contaminação, é restrito, devido à informação insuficiente, compromisso ambíguo com a relação, e insegurança relacional para discutir a prática segura do sexo.

\section{MÉTODO Casais Participantes}

Foram entrevistados 15 casais heterossexuais que estavam realizando testagem para HIV em Centro de Testagem e Aconselhamento (CTA) do Estado, em um período compreendido entre os anos 2001 e 2002, conforme descrição apresentada na Tabela 1. Os casais residiam em bairros da periferia de Porto Alegre ou da região metropolitana, fazendo parte dos chamados grupos populares (camadas de renda baixa e média-baixa). 
Tabela 1: Características gerais dos casais

\begin{tabular}{|c|c|c|c|c|c|c|c|c|c|c|c|c|}
\hline \multirow[t]{2}{*}{ Casal } & \multicolumn{2}{|c|}{ Idade } & \multirow[t]{2}{*}{$\begin{array}{l}\text { Tempo de } \\
\text { Casamento }\end{array}$} & \multirow[t]{2}{*}{$\begin{array}{l}\text { Filhos em } \\
\text { comum }\end{array}$} & \multicolumn{2}{|c|}{$\begin{array}{l}\text { Casamentos } \\
\text { Anteriores }\end{array}$} & \multicolumn{2}{|c|}{$\begin{array}{l}\text { Filhos de } \\
\text { casamentos } \\
\text { anteriores }\end{array}$} & \multicolumn{2}{|c|}{$\begin{array}{l}\text { Escolaridade } \\
\qquad \star \star \star\end{array}$} & \multicolumn{2}{|c|}{ Profissão } \\
\hline & $\mathrm{H}^{*}$ & M & & & $\mathrm{H}$ & M & $\mathrm{H}$ & $\mathrm{M}$ & $\mathrm{H}$ & M & $\mathrm{H}$ & M \\
\hline 1 & 18 & 21 & $7 m$ & 0 & 0 & 1 & 0 & 0 & $\mathrm{FI}$ & $\mathrm{F}$ & Comércio da família & Desempregada \\
\hline 2 & 37 & 33 & $2 a$ e $3 m$ & Grávida & 1 & 2 & 2 & 3 & $?$ & $?$ & $\begin{array}{l}\text { Desempregado } \\
\text { Foi garçon }\end{array}$ & $\begin{array}{l}\text { Desempregada } \\
\text { Foi vendedora e } \\
\text { dona de creche }\end{array}$ \\
\hline 3 & 35 & 35 & $14 a$ & 2 & 0 & 0 & 0 & 0 & $?$ & $?$ & Microempresário & Microempresária \\
\hline 4 & 38 & 36 & $10 a$ & 1 & 1 & 0 & 1 & 0 & MI & SI & $\begin{array}{l}\text { Desempregado } \\
\text { Foi viajante e mecânico }\end{array}$ & $\begin{array}{l}\text { Microempresa } \\
\text { decoração }\end{array}$ \\
\hline 5 & 25 & 27 & $2 a$ e $6 m$ & 0 & 1 & 0 & 0 & 0 & M & MI & Segurança & Aux. Enfermagem \\
\hline 6 & 34 & 37 & $3 a$ e $6 m$ & 0 & 1 & 1 & 1 & 2 & $\mathrm{FI}$ & $\mathrm{FI}$ & $\begin{array}{l}\text { Agricultura, } \\
\text { no presídio }\end{array}$ & $\begin{array}{l}\text { Aposentada. } \\
\text { Trabalha para } \\
\text { fábrica de calçados } \\
\text { em casa }\end{array}$ \\
\hline 7 & 33 & 25 & $4 a$ & $\begin{array}{c}1 \\
\text { Grávida }\end{array}$ & 0 & 0 & 0 & 0 & $\mathrm{FI}$ & $\mathrm{FI}$ & $?$ & Dona de casa \\
\hline 8 & 32 & 17 & $2 a$ e $5 m$ & Grávida & $?$ & 0 & 0 & 0 & $\mathrm{FI}$ & FI & Operário construção civil & Dona de casa \\
\hline 9 & 26 & 18 & $1 a$ & 0 & 1 & 0 & 0 & 0 & MI & FI & Músico & Dona de Casa \\
\hline 10 & 35 & 28 & $2 a$ & 0 & 2 & 2 & 3 & 2 & $S$ & M & Vendedor & Vendedora \\
\hline 11 & 31 & 48 & $10 a$ & 0 & 0 & 1 & 0 & 3 & $?$ & $?$ & Comércio da família & $\begin{array}{l}\text { Telefonista } \\
\text { aposentada }\end{array}$ \\
\hline 12 & 48 & 66 & $\begin{array}{l}\text { 5a separados } \\
\text { há } 3 m\end{array}$ & 0 & 1 & 1 & 2 & 3 & $\mathrm{~F}$ & $\mathrm{FI}$ & Motorista ônibus & $\begin{array}{l}\text { Costureira } \\
\text { aposentada }\end{array}$ \\
\hline 13 & 24 & 20 & $5 a$ & 1 & 1 & 0 & 0 & 0 & $\mathrm{FI}$ & $\mathrm{FI}$ & $\begin{array}{l}\text { Auxiliar de produção } \\
\text { Desempregado }\end{array}$ & $\begin{array}{l}\text { Empregada } \\
\text { doméstica }\end{array}$ \\
\hline 14 & 23 & 31 & $8 m$ & Grávida & 2 & 1 & 4 & 2 & $\mathrm{FI}$ & $\mathrm{FI}$ & Oficina mecânica & Dona de Casa \\
\hline 15 & 24 & 22 & $2 a 6 m$ & Grávida & 0 & 0 & 0 & 0 & $M$ & $M$ & Informática & Vendedora \\
\hline
\end{tabular}

\section{Instrumento e Procedimentos}

Os dados foram obtidos por uma entrevista semiestruturada. Um modelo do protocolo da entrevista utilizado encontra-se no Anexo A. Os casais informantes foram convidados a participar deste estudo a partir de seu contato com o Centro de Testagem e Aconselhamento (CTA-COAS) Estadual, localizado junto ao Ambulatório de Dermatologia Sanitária do Estado do RGS (ADS). Os convites para participação na pesquisa foram apresentados durante o aconselhamento pós-teste pelos próprios aconselhadores, com a distribuição de folhetos que informavam sobre a pesquisa e o perfil dos casais candidatos; ou após palestra que antecedia a testagem, pela própria entrevistadora. Solicitava-se que os casais permanecessem na sala, apresentavam-se os objetivos da pesquisa com distribuição de Folheto Informativo aos Casais, esclarecendo que, após a coleta de sangue, aqueles que desejassem participar retornariam à sala de palestra para a entrevista. As entrevistas foram registradas em gravação de áudio e transcritas literalmente.

\section{Critério de Análise}

$\mathrm{O}$ material obtido nas entrevistas foi submetido a uma análise qualitativa temática, dividida em três etapas: 1) descrição compreensiva das respostas dos casais à entrevista, elaborada de acordo com a demarcação exaustiva das falas em unidades temáticas para que nada do que foi dito fosse deixado de fora e nem engrandecido ou diminuído por escolhas do pesquisador (Gomes, 1998); 2) identificação de temas que se apresentam com potencialidade para esclarecer os elos que interligam as experiências vividas pelo casal, de acordo com os elementos fornecidos pelo contexto da descrição, designada por Patton (1990) de análise indutiva; e 3) análise crítica ou interpretativa dos temas identificados no confronto entre descrição, literatura e experiência do pesquisador com a situação em foco (Kvale, 1994). As três etapas mencionadas são passos reflexivos imbricados, cada passo contendo os três. Procura-se manter, ao longo da análise, o enfoque qualitativo, isto é, excluindo-se quaisquer apoios quantitativos de falas ou falantes, mantendo-se coerentes às especificações de possibilidades. Este critério de análise qualitativa tem suas raízes no movimento fenomenológico (Spiegelberg, 1982), enquanto critério operacional e ético para acesso à experiência do outro (participantes da pesquisa) e de si mesmo (a compreensão dos pesquisadores do que está sendo dito e a estrutura induzida e construída para a organização do material). Em outras palavras, as três etapas reflexivas servem como método de abordagem e análise, uma forma sistemática e sistêmica de acesso à realidade estudada. Os dados obtidos e as interpretações propostas dialogam com a literatura 
pertinente procedente de diferentes abordagens. Espera-se, assim, abrir horizontes para novas e diferentes análises, e novas formas de compreender e intervir na situação problema.

\section{RESULTADOS}

A apresentação dos resultados está dividida em duas partes. A primeira traz uma síntese dos motivos que levaram os casais à realização da testagem para HIV. A segunda é uma análise qualitativa em três etapas de percepção de risco.

\section{Parte 1: Motivos de Testagem}

Os motivos que levaram os casais deste estudo a procurar o teste para HIV podem ser reunidos em três grupos: 1) percepção de risco, 2) encaminhamento médico, 3) pressão do grupo social (Tabela 2). A percepção de risco verbalizada estava relacionada a relações sexuais desprotegidas anteriores ao atual relacionamento, uso de drogas injetáveis, soropositividade do atual cônjuge, e situação de acidente de trabalho, isto é, a consciência de pertencer a um grupo de risco. O encaminhamento médico estava relacionado à presença de doenças oportunistas, a longos períodos de adoecimento sem definição do diagnóstico e à rotina pré-natal de gestantes. A pressão do grupo social explicitava-se na forma de boatos, surgidos no âmbito familiar ou na comunidade do casal, insinuando que um dos cônjuges estaria com AIDS. Nestes casos, o exame tinha como objetivo provar a falsidade de tais boatos.

Os motivos apresentados não eram excludentes. Em certas situações foi necessária a sobreposição de dois deles para que o casal efetivamente tomasse a decisão de realizar o exame. Exemplificam esta posição, as alegações apresentadas pelos casais 1, 2 e 14 para fazer o teste. O período pré e pós testagem caracterizou-se por uma ambivalência em querer ou não querer saber os resultados. $\mathrm{O}$ casal 8 testou-se, mas levou onze meses para decidir saber, deparandose com resultados positivos em um dos cônjuges.

Tabela 2: Motivo do exame e sorologia indicada em exame

\begin{tabular}{|c|c|c|c|}
\hline \multirow[t]{2}{*}{ Casal } & \multirow[t]{2}{*}{ Motivo do exame } & \multicolumn{2}{|c|}{ Sorologia* } \\
\hline & & & M \\
\hline 1 & $\begin{array}{l}\text { História de risco, em ambos os cônjuges, de relações heterossexuais desprotegidas, principalmente } \\
\text { ele, cuja última namorada era usuária de drogas. O casal conversava sobre fazer o teste, mas sempre } \\
\text { adiava essa decisão, até surgir um boato, na vizinhança em que mora e na cidade natal dele, de que } \\
\text { ele estaria com AIDS. Isso fez com que ele tomasse a decisão de fazer o exame. Ao acompanhá-lo, } \\
\text { ela decidiu também se testar. }\end{array}$ & - & - \\
\hline 2 & $\begin{array}{l}\text { Encaminhamento médico por doenças oportunistas. Ele percebia risco por ser usuário de drogas } \\
\text { injetáveis - muitos amigos haviam morrido - mas só fez o teste por recomendação médica. Buscou o } \\
\text { resultado do } 1^{\circ} \text { exame após um ano. }\end{array}$ & + & $\mathrm{J}$ \\
\hline 3 & Encaminhamento médico por doença oportunista (Ele). & + & - \\
\hline 4 & Encaminhamento odontológico após longo período de adoecimento sem definição do diagnóstico (Ele). & + & - \\
\hline 5 & Acidente de trabalho. Ela é auxiliar de enfermagem e picou-se com agulha. & - & - \\
\hline 6 & $\begin{array}{l}\text { Encaminhamento médico por doença oportunista (Ele). Havia feito o teste há mais tempo, mas o } \\
\text { presídio não o informou do resultado até ter tuberculose, há três meses. }\end{array}$ & + & ? \\
\hline 7 & Encaminhamento médico após anos de adoecimento sem definição do diagnóstico (Ele). & + & - \\
\hline 8 & $\begin{array}{l}\text { Percepção de risco por uso de drogas injetáveis (Ele). O casal fez o primeiro exame há um ano e } \\
\text { buscou o resultado após onze meses. Fazem novo exame porque mantiveram práticas de sexo } \\
\text { desprotegido no período; ela engravidou. }\end{array}$ & + & $\mathrm{J}$ \\
\hline \multirow[t]{2}{*}{9} & $\begin{array}{l}\text { Percepção de risco por experiências sexuais desprotegidas anteriores ao casamento (Ele e ela). Houve } \\
\text { preocupação desde que começaram a transar sem preservativo. }\end{array}$ & $?$ & $?$ \\
\hline & & & cont. \\
\hline \multirow[t]{2}{*}{ Casal } & Motivo do exame & \multicolumn{2}{|c|}{ Sorologia* } \\
\hline & & $\mathrm{H}$ & M \\
\hline 10 & $\begin{array}{l}\text { Percepção de risco pelo cônjuge ser soropositivo. Ele está fazendo o teste pela primeira vez por estar } \\
\text { convivendo há cerca de dois anos com companheira soropositiva (há } 10 \text { anos), apesar de sempre } \\
\text { terem usado preservativo. }\end{array}$ & - & + \\
\hline 11 & $\begin{array}{l}\text { Motivação pessoal por perda de peso e sintomas popularmente associados à AIDS (Ela). Vê risco em } \\
\text { transfusões de sangue realizadas no passado. }\end{array}$ & $?$ & $?$ \\
\hline 12 & $\begin{array}{l}\text { Contradizer boatos. (Ele e ela) Ele recebeu bilhete avisando que ela está com AIDS. Ela recebeu } \\
\text { telefonema dizendo que ele está com AIDS. Ele fez o exame para deixá-la mais tranqüila, ela para ter } \\
\text { uma prova para os familiares, caso o boato estoure. }\end{array}$ & $?$ & $?$ \\
\hline 13 & $\begin{array}{l}\text { Contradizer boatos (Ele). A mãe dela soube por um espírita que ele está com o vírus, "está tomado", } \\
\text { que pegou através do crack. }\end{array}$ & $?$ & ? \\
\hline 14 & $\begin{array}{l}\text { Encaminhamento médico - Gestante. Ela refere muito medo de ter contraído o vírus HIV com seu } \\
\text { antigo companheiro, que era casado e tinha outras amantes além dela. Tinha vontade de fazer o teste, } \\
\text { mas esse desejo só se concretizou a partir da solicitação médica, por ela estar grávida. }\end{array}$ & $?$ & $?$ \\
\hline 15 & Encaminhamento médico - Gestante. & $?$ & $?$ \\
\hline & $\begin{array}{r}\text { J: } \\
\text { J: Período de janela imunológica (relativo aos três primeiros mese } \\
\text { quando podem não ser dete } \\
\text { ?: Resultado não disponível no mom }\end{array}$ & & $\begin{array}{l}\text { Mulher } \\
\text { nti-HIV } \\
\text { nti-HIV } \\
\text { ecção, } \\
\text { orpos) } \\
\text { revista }\end{array}$ \\
\hline
\end{tabular}

Antes de realizar o teste, os participantes já possuíam informações generalizadas sobre AIDS e formas de prevenção. Elas eram provenientes de campanhas veiculadas na mídia (TV, jornais, reportagens e 
revistas), de amigos, da escola e de acompanhamento médico. As principais formas de transmissão citadas foram: relações sexuais, uso de drogas injetáveis e transfusões de sangue. Sem especificação quanto ao sangue compartilhado, a idéia trazida é que a droga em si transmitiria a doença. Uma forma de contaminação de certo modo desconhecida entre eles foi a transmissão vertical da mãe para o bebê. Referências à transmissão por relações homossexuais não foram enfatizadas. Havia dúvidas esparsas sobre os riscos de contrair o HIV beijando na boca, pegando o filho no colo, bebendo no mesmo copo, dando as mãos, ou em uma cesariana. Como forma de prevenção, foram referidos o uso de preservativos (principalmente masculinos, mas também femininos) e o não uso de drogas (ao invés do não compartilhamento de seringas). A diferença entre ser portador do vírus HIV e ser doente de AIDS nem sempre era conhecida, levando à crença de que o contato com o vírus levaria imediatamente à enfermidade, à degeneração física e à morte. Também havia desconhecimento sobre o período de janela imunológica e sobre a possibilidade de reinfecção entre portadores. Casais com o mesmo tipo de informação podiam tanto se considerar bem informados quanto mal informados. Em alguns casais, o nível de informação não coincidia e cada cônjuge possuía informações diferentes.

\section{Parte 2: Análise Qualitativa em Três Etapas da Percepção de Risco \\ Primeira Etapa: Descrição Compreensiva}

As entrevistas mostraram três modalidades de percepção de risco: 1) admissão de suscetibilidade; 2) afïmação de não suscetibilidade; e 3) inserção contraditória e ambígua. Essas modalidades estão entrelaçadas com a possibilidade de compartilhamento ou não do risco percebido entre o casal.

A primeira modalidade é a de casais que compartilham a mesma percepção de risco, considerando tanto os fatores pessoais (situações de seu próprio passado ou presente), quanto os riscos relacionados ao cônjuge (situações de vida do parceiro). Esses casais reconheciam que haviam se exposto a risco por meio de relações sexuais desprotegidas e de atividades profissionais (risco ocupacional). Por exemplo, nos casais 1 e 9, ambos os cônjuges preocupavam-se com as experiências sexuais desprotegidas anteriores a este relacionamento. O casal 5 reconhecia risco ocupacional em ambos os cônjuges: ela, por ser auxiliar de enfermagem, ele, por ser viajante, permanecendo semanas afastado de casa só na convivência de homens, o que incentivaria o sexo extraconjugal.

A segunda modalidade é a de casais em que ambos os cônjuges não se percebem em risco, nem quanto a si, nem quanto ao parceiro(a). Os argumentos são indicadores de uma percepção de risco baseada em critérios parciais ou mesmo equivocados: não fazer parte de grupo de risco, conhecer os parceiros anteriores e estes não terem adoecido, não ter filhos que pareçam estar doentes, estar, atualmente, ou vir de um relacionamento estável, ter tido poucas parcerias sexuais, ter casado virgem e este ser o único parceiro (somente mulheres), não ser usuário de drogas, ser doador de sangue. Esses casais tendem a reconhecer alguns riscos específicos, ignorando outros, como ilustram as histórias a seguir.

A história do Casal 4 exemplifica a situação em que o passado sexual desprotegido é desconsiderado baseando-se na noção de grupo de risco. Durante o casamento ele teve algumas "amantes" e não se preocupava com os cuidados de prevenção. Ele passou a usar preservativo em relações casuais por informações obtidas na mídia que diziam que "AIDS mata". A medida que a relação com a amante ficava estável, a tendência era abdicar do uso.

A história do Casal 13 exemplifica como as práticas sexuais anteriores ao relacionamento são descartadas da noção de risco. Percebe-se que as relações extraconjugais e as relações sexuais prévias nem sempre eram levadas em conta como situações de risco. Os argumentos para isso envolviam a crença de que se pode perceber o desgaste físico de uma pessoa com o vírus da AIDS, ou que a infecção seria visível em filhos nascidos dessas relações anteriores. Há em tais histórias uma dificuldade recorrente em reconhecer a diferença entre ser portador do vírus HIV ou doente de AIDS sem sintomas, e doente de AIDS em fase terminal.

A história do Casal 7 mostra como a confiança na habilidade de selecionar parceiros não infectados encobre o risco das relações seqüenciais estáveis desprotegidas. O argumento de que teve poucas relações sexuais, ou que sempre foi fiel a cada namorada também é utilizado. O risco existiria somente para os promíscuos, mas a definição de promiscuidade pode ser muito particular:

$\mathrm{H}$ : Eu acho que poderia ter a ver com a minha vida anterior, no caso. Só que eu acho estranho porque eu nunca fui uma pessoa de levar a vida promiscuamente [...] Eu acredito que uma pessoa prá poder se contaminar com uma doença ela, geralmente, com doenças sexualmente transmissíveis, ela tem que viver uma vida promíscua. Ela tem muita chance de se contaminar com muita coisa, ela... eu digo, penso... e diante dessas dúvidas todas...

\section{Pesquisador: Mas tu tiveste namoradas, então?}

H: Ah, isso eu tive; umas cinqüenta ou mais na vida.

Uma possibilidade, ainda, era a percepção de risco estar relacionada aos filhos, mas não ao próprio casal, como exemplifica excerto da entrevista do casal 3.

H: Não, a gente só falava [sobre camisinha]. A gente só falava. Até o meu gurizinho, o meu filho, né [dirigindo-se à esposa]? Ele tem oito anos, daí até ele diz: "né mãe, quando tem namorada tem que tê camisinha"; "não, tem que tê camisinha!". A gente conversa, tudo, explica. 


\section{P: Mas na relação de vocês nunca fez parte?}

M: Não.

H: Não, nunca fez parte [fala mais baixinho].

Ainda dentro da segunda modalidade de percepção de risco - casais em que ambos os cônjuges não se percebem em risco - podemos incluir os exemplos de mulheres, como no caso do Casal 7, que se reportaram ao fato de terem casado virgens, ou do atual companheiro ter sido o primeiro parceiro sexual, referindo-se à ausência de risco em suas vidas. Também o fato de doar sangue foi relacionado à não admissão de suscetibilidade. Ainda que não seja feita explicitamente com a intenção de identificar a sorologia para HIV, a doação de sangue acaba servindo para esse fim. Desta forma, o risco do passado é descartado, pois, se houvesse a infecção, esta apareceria no sangue doado.

A terceira modalidade é a percepção de risco não compartilhada, em que os casais diferem em suas avaliações: um dos cônjuges avalia risco e o outro não. As histórias dos Casais 8 e 14, a seguir, exemplificam essa situação, que traz um desafio específico para a prevenção: as situações em que um cônjuge avalia o risco e quer assumir práticas preventivas, mas o outro ou desconhece ou desvaloriza essa preocupação.

O homem, no Casal 8, sabia que estava em situação de risco por uso de drogas injetáveis. Ele suspeitava que já podia estar infectado, ao menos, há dez anos. A esposa não se considerava em situação de risco, apesar de saber que o marido era usuário de drogas injetáveis. Iniciaram o relacionamento usando preservativo por iniciativa do marido, conforme indicado no excerto que seque:

\section{$P:$ E o que fez vocês usarem camisinha, então, no início do namoro?}

H: Prevenir. Evitar que ela se contaminar.

M: Mas eu não sabia que ele tinha, mas eu aceitava. Ele falava pra usar camisinha porque ele tinha medo de engravidar, e eu não queria engravidar.

No casal 14, o homem nunca pensou em AIDS. Desvalorizava o risco, dizendo que só "transou" com as duas ex-esposas. A parceira considerava-se suscetível, por não ter usado preservativo com parceiros

anteriores, principalmente com o homem com quem viveu como amante por sete anos e que tinha, ao menos, três mulheres ao mesmo tempo. Também reconhecia o risco relacionado ao cônjuge, referindo que o parceiro teve outras mulheres e a fidelidade delas não podia ser garantida. $O$ não compartilhamento da percepção de risco estava associado à dificuldade de conversar sobre o problema e de assumir abertamente o uso do preservativo.

\section{Segunda Etapa: Análise Indutiva}

A ação de determinar a sorologia em um dos cônjuges põe em avaliação a própria vida, a vida do parceiro e a relação conjugal. Nos casais estudados, constatou-se: 1) que o domínio de informações era suficiente para reconhecer risco em relações sexuais desprotegidas; 2) que as informações poderiam ser desconsideradas ou transformadas por uma interpretação particular, excluindo o cônjuge e o relacionamento conjugal atual do âmbito da percepção de risco; e 3) que as percepções quanto ao risco podem ou não ser compartilhadas. Desta forma, a percepção de risco apresenta-se em dois níveis sobrepostos. $\mathrm{O}$ primeiro referindo-se às percepções individuais, e o segundo às percepções comuns ao casal. O segundo nível constitui, assim, o risco casal, tema pouco desenvolvido na literatura, e que passa a ser o ponto focal da próxima etapa.

\section{Terceira Etapa: Análise Crítica}

As percepções comuns ao casal não são necessariamente desencadeadoras da ação de procurar a testagem. Pelo contrário, o controle ou estímulo do grupo social, ao reconhecer os sinais do adoecimento, parece levar a ações mais efetivas. Tais percepções podem se transformar em crenças nas quais a racionalidade do comportamento individual contrapõe-se à noção de vulnerabilidade, priorizando fatores sociais e culturais (Knauth, Victora \& Leal, 1998). Os exemplos sobre a percepção de risco mostram a importância das inter-relações e sobreposições das percepções individuais na formação de uma percepção de risco do casal que pode ser compartilhada ou não. Essa, por seu turno, está permeada pelas noções do grupo social dos casais quanto ao adoecimento e ao sexo; daí a utilização de critérios parciais e equivocados para a percepção de risco, predominantes na modalidade na qual os cônjuges não se percebem em risco.

No contexto de cultura popular (Knauth \& cols., 1998) o risco faz parte da natureza aleatória dos eventos, sejam estes sociais (como perder emprego) ou biológicos (pegar filho, pegar doença). Para as mulheres, especificamente, associar risco e sexualidade é parte do cotidiano (risco de engravidar, risco de perder filho, de perder marido). $\mathrm{O}$ risco passa a ter uma dimensão de destino: "no sentido de evento contingente, dado que sua possibilidade está sempre presente no mundo no qual o indivíduo se insere e de que é parte" (Knauth \& cols., 1998, p. 193). Assim, o risco de contrair uma doença, incluindo a AIDS, pode fazer parte do custo intrínseco de qualquer relação. É um evento que pode ocorrer a partir da relação (sexual ou pessoal) entre um homem e uma mulher.

$\mathrm{O}$ risco relacionado ao cônjuge pode ou não ser reconhecido. Quando reconhecido, parece haver um esforço para encobri-lo, pois há outros custos que precisam ser emocionalmente considerados. Além disso, se o poder decisório está nas mãos do destino, há que considerar que a relação amorosa estaria permeada do mesmo poder. Como pode o ser amado trazer riscos? A observação desses dois níveis e a avaliação da coincidência ou não das percepções dos 
cônjuges assume grande importância para aqueles que trabalham com casais e, de modo amplo, para a prevenção.

$\mathrm{Na}$ fala dos casais deste estudo, a fidelidade é parte intrínseca do ser casal, e a quebra da fidelidade implica quebra do relacionamento. Assim, aceitar a inclusão do relacionamento amoroso estável no contexto do risco exigiria uma avaliação racional que não faz parte do ideal do amor romântico. Na construção da relação amorosa, cada casal estabelece um padrão relacional com regras implícitas, explícitas, e de transação. O padrão relacional determina quem estabelece oficialmente as regras, quem as aplica, e quem as faz respeitar (Anton, 1998, 2002). Na interpretação dos autores, é com base na neste padrão relacional que cada casal se comportará diante da possibilidade da infecção por HIV. Como visto na descrição, quando houve convergência na avaliação da suscetibilidade entre os membros da díade, o diálogo foi mais fácil. Aparentemente, as regras relacionais tendiam à simetria, permitindo que tanto o homem quanto a mulher, falassem sobre o assunto. Entretanto, quando houve divergência na suscetibilidade percebida, as regras de transação tendiam a limitar o diálogo sobre os conteúdos do risco e da prevenção. A inserção contraditória e ambígua indica dificuldades no nível da relação conjugal mais do que no nível de conhecimento sobre conteúdos de HIV/AIDS.

O risco do rompimento da relação é um custo emocional importante, principalmente para as mulheres, que tendem a adotar comportamentos de risco para a manutenção do relacionamento afetivo, inclusive no sentido de não buscar o teste, como também constatado no estudo de Maman e cols. (2001). O diálogo com o parceiro sobre prevenção pode levar a decisões mais amplas, sobre a própria manutenção do relacionamento. Se a conversa sobre prevenção não for suportável para qualquer um dos cônjuges, ela deixa de ser prioritária e o convívio com a ambigüidade e a dúvida se mantém.

\section{Conclusões}

A análise mostrou ser difícil para um casal que inicia ou já está em uma relação com alguma estabilidade considerar a possibilidade do HIV/AIDS fazer parte de sua relação amorosa. Tal pensamento, ainda que muito realista em nossos dias, contraria fundamentalmente a imagem idealizada do objeto de amor romântico: como poderia o meu escolhido trazer consigo tamanho risco? Os indícios de suspeita podem levantar a necessidade de testagem, que mesmo assim poderá passar por adiamentos quanto às providências para exame e conhecimento do resultado.

Quais as implicações para a prevenção considerando as diferentes modalidades de percepção de risco entre a díade conjugal? Mesmo casais que admitem estar suscetíveis à AIDS são ambivalentes ao atendimento de ações preventivas. Esse grupo pode beneficiar-se de campanhas que apresentem modelos efetivando a prevenção, conversando, associando a prevenção com comprometimento com o relacionamento. No entanto, o maior desafio está entre casais que não compartilham a mesma percepção de risco. São aqueles que não estão sensibilizados à questão da AIDS, tornando-se igualmente cúmplices na falta de compromisso com a prevenção. Esses casais parecem depender de uma sensibilização para além da informação pura e simples; pois é necessário que se reconheçam como possíveis portadores. Eles podem beneficiar-se tanto de sensibilização individual, quanto do desenvolvimento de habilidades de prevenção em grupos de pares ou grupos de casais. Há, ainda, os casais que diferem em sua avaliação: um dos cônjuges avalia risco e o outro não. Essa discrepância parece ser indicativa de tensões e problemas na relação conjugal. São estes os casais que poderiam se beneficiar de procedimentos psicoterápicos voltados para a relação conjugal, trabalhando os acordos e desacordos explícitos e implícitos e potencializando o diálogo e o equilíbrio nas trocas do casal. Principalmente com este terceiro grupo, mas também com os demais, torna-se necessário trabalhar fortemente questões de gênero, potencializando a tomada de decisão das mulheres e desmistificando a imagem de virilidade associada ao comportamento não preventivo dos homens.

As análises apresentadas permitem sugerir que campanhas preventivas com foco nas comunidades podem favorecer a criação de espaços e de habilidades de diálogo entre os casais. $\mathrm{O}$ fato de o assunto poder ser público e compartilhado em diferentes espaços torna menos ansiogênicos o diálogo e as ações decorrentes. Mesmo quando o grupo social estimula a testagem motivada pelo preconceito, "para provar que não se está infectado", o efeito é tornar as conversas sobre o assunto necessárias, permitindo trocas que poderão ser mantidas, se também reforçadas por propostas preventivas voltadas para casais. Sugere-se, ainda, a realização de estudos voltados para casais com relação à temática HIV/AIDS, em especial que se analisem os possíveis efeitos preventivos da realização conjunta da testagem. Da mesma forma, seria interessante a realização de estudos que comparassem casais que buscam juntos a testagem e pessoas que estão em relações estáveis, mas que realizam a testagem sozinhas casais. Tais estudos poderiam auxiliar na construção de alternativas para a prevenção, utilizando espaços de intervenção já estabelecido no sistema público de saúde. Da mesma forma, poderiam ser desenvolvidos estudos comparando casais homossexuais e heterossexuais estáveis, em sua experiência na comunicação e interação relacionada a essa temática.

\section{Referências}

Anton, I. L. C. (1998). A escolha do cônjuge: Um entendimento sistêmico e psicodinâmico. Porto Alegre: Artes Médicas.

Anton, I. L. C. (2002). Homem e mulher: Seus vínculos secretos. Porto Alegre: Artes Médicas.

Barbosa, R. H. S. (1995). As mulheres, a AIDS e a questão metodológica: Desafios. Em D. Czeresnia, R. H. S. Barbosa, \& S. Monteiro (Orgs.), AIDS: Pesquisa social e educação (pp. 6583). São Paulo/Rio de Janeiro: Hucitec/Abrasco.

Both, N. S. (1997). Mulheres casadas, risco e AIDS: Um estudo junto a clubes de mães. Dissertação de mestrado não 
publicada, Curso de Pós-Graduação em Sociologia, Universidade Federal do Rio Grande do Sul. Porto Alegre, RS.

Brasil (2000). Comportamento sexual da população brasileira e percepções do HIV/AIDS. Brasília: CN - DST/AIDS, Ministério da Saúde.

Buunk, B. \& Bakker, A. B. (1997). Commitment to the relationship, extradiadic sex, and AIDS prevention behavior. Journal of Applied Social Psychology, 27, 1241-1257.

Campos, R. C. P. (1998). AIDS: trajetórias afetivo-sexuais das mulheres. Em C. Bruschini, \& H. B. de Hollanda (Orgs.), Horizontes plurais: novos estudos de gênero no Brasil (pp. 85-109). São Paulo: FCC; Ed. 34.

Chippindale, S. \& French, L. (2001). ABC of AIDS: HIV counselling and the psychosocial management of patients with HIV or AIDS. British Medical Journal, 322(7301), 1533-1535.

Choi, K. H.; Catania, J. A. \& Dolcini, M. M. (1994). Extramarital sex and HIV risk behavior among US adults: Results from the National AIDS Behavioral Survey. American Journal of Public Health, 84, 2003-2007.

Gomes, W. B. (1998). A entrevista fenomenológica e o estudo da experiência consciente. Em W. B. Gomes (Org.), Fenomenologia e pesquisa em psicologia (pp. 19-44). Porto Alegre: Ed. Universidade/UFRGS.

Guimarães, C. D. (1994). Mulheres, homens e AIDS: O visível e o invisível. Em R. Parker; C. Bastos; J. Galvão, \& J. S. Pedrosa (Orgs.), A AIDS no Brasil (pp. 217-230). Rio de Janeiro: Relume-Dumará/Abia.

Knauth, D. R. (1997). O que pensam as mulheres sobre a infecção pelo HIV: Uma abordagem antropológica. Saúde: Revista do NIPESC/UFRGS, 2, 7-18.

Knauth, D. R.; Victora, C. G. \& Leal, O. F. (1998). A Banalização da AIDS. Horizontes Antropológicos, 9, 171-202.

Kvale, S. (1994). Ten standard objections to qualitative research interviews. Journal of Phenomenological Psychology, 25, 147-173.

Levine, O. H.; Britton, P. J.; James, T. C.; Jackson, A. P.; Hobfoll, S. E. \& Lavin, J. P. (1993). The empowerment of women: A key to HIV prevention. Journal of Community Psychology, 21, 320-334.
Maman, S.; Mbwambo, J.; Hogan, N. M.; Kilonzo G. P. \& Sweat, M. (2001). Women's barriers to HIV-1 testing and disclosure: Challenges for HIV-1 voluntary counselling and testing. AIDS-Care, 13(5), 595-603.

Maxwell, C. \& Boyle, M. (1995). Risky heterosexual practices amongst women over 30: Gender, power and long term relationships. AIDS-Care, 7, 277-293.

Obbo, C. (1993). HIV transmission: Men are the solution. Population and Environment: A Journal of Interdisciplinary Studies, 14, 211-243.

Painter, T. (2001). Voluntary counseling and testing for couples: A high-leverage intervention for HIV/AIDS prevention in subSaharan Africa. Social Science and Medicine, 53, 1397-1411.

Patton, M. Q. (1990). Qualitative evaluation methods. Beverly Hills: Lage Publications.

Pimenta, M. C.; Passarelli, C. A.; Brito, I. \& Parker, R. (2002). As pesquisas sociais sobre sexualidade e AIDS no Brasil: entre a demografia e a cultura sexual (1980-2000). Em R. Parker \& V. Terto Jr. (Orgs.), Aprimorando o debate: Respostas sociais frente à AIDS: Anais do Seminário Pesquisa em DST/AIDS: Determinantes sócio-demográficos e cenários futuros (p. 323). Rio de Janeiro: ABIA.

Pitts, M.; Bowman, M. \& McMaster, J. (1995). Reactions to repeated STD infections: Psychosocial aspects and gender issues in Zimbabwe. Social Science and Medicine, 40, 12991304.

Roth, D. L.; Stewart, K. E.; Clay, O. J.; Van-der-Straten, A.; Karita, E. \& Allen, S. (2001). Sexual practices of HIV discordant and concordant couples in Rwanda: Effects of a testing and counseling programme for men. International Journal of STD and AIDS, 12(3), 181-188.

Spiegelberg, H. (1982). The phenomenological movement. The Hague: Martinus Hijhoff Publishers.

Enviado: 15.11 .2003 Revisado: 10.05.2004 Aceito: 25.05.2004

\section{Nota:}

${ }^{1}$ Os autores agradecem as sugestões dos pareceristas que contribuíram enormente para a clareza e elegância do texto. Também informa que parte das sugestões para futuros estudos foram gentilmente enviadas por um dos pareceristas.

\section{Sobre os autores:}

Lirene Finkler: Psicóloga e Mestra em Psicologia pela Universidade Federal do Rio Grande do Sul; Terapeuta de Casais e Famílias. Desenvolve atividades junto à Prefeitura Municipal de Porto Alegre.

Pricilla Braga: Estudante de Psicologia e Bolsista de Iniciação Científica (FAPERGS) - UFRGS

William B. Gomes: Professor de Epistemologia e História da Psicologia no Instituto de Psicologia da Universidade Federal do Rio Grande do Sul, Mestrado e Doutorado pela Southern Illinois University Carbondale. Fundador e Primeiro Editor da Revista Psicologia: Reflexão e Crítica. Bolsista de Produtividade em Pesquisa do CNPq. Tem publicado nas áreas de psicoterapia, história da psicologia, e desenvolvimento humano.

Endereço eletrônico: gomesw@ufrgs.br - Site: http: www.psicologia.ufrgs.br/grupo_pesq/index.htm 


\section{ANEXO A - PROTOCOLO DE ENTREVISTA}

Apresentação da pesquisa: Eu sou psicóloga e estou estudando o tema da AIDS e o relacionamento de casais.

[Referência à necessidade de que ambos concordem em participar do estudo. Apresentação do Consentimento Informado] Para este estudo eu gostaria que vocês pudessem me contar um pouco da vida de vocês como casal. Pode ser? Nossa entrevista deve levar cerca de uma hora e meia. Eu gostaria de poder gravar/filmar nossa conversa. Todo material gravado é sigiloso, as pessoas não serão identificadas no trabalho. Vocês têm alguma pergunta?

Tópicos da entrevista

\section{História do relacionamento desde seu início até o momento atual.}

Como vocês se conheceram? Como era no início da relação de vocês? Como cada um foi se adaptando à vida juntos? Que coisas vocês tiveram que negociar? Como foi? Podem exemplificar?

\section{Filosofia sobre a relação a dois. Como os membros do casal percebem e descrevem a natureza das} relações emocionais que mantém entre si.

O que é, para vocês, estar casado, ou ser um casal? Em que vocês diriam que está baseada a relação de vocês? Quais os pontos fortes da relação de vocês? A fidelidade é fundamental?

\section{Vivência da possibilidade de contaminação por HIV. Práticas preventivas anteriores e posteriores à} testagem.

A existência do vírus foi discutida na relação? Quando passaram a considerar-se vulneráveis à contaminação? Quem se preocupou? De onde veio a preocupação? Foi estabelecida alguma prática preventiva? Quem propôs? Quem decidiu? Se não foi estabelecida nenhuma prática de prevenção, o que cada um pensa e sente sobre isso? Como foi a experiência de realizar a testagem? A possibilidade da contaminação trouxe alguma modificação nas práticas preventivas do casal? Como foram negociadas?

Fechamento: A entrevista segue conforme a disponibilidade do casal em continuar seu depoimento sobre 0 tema da pesquisa. Por fim, a pesquisadora agradece a colaboração e encerra a entrevista. 